\title{
A CONTABILIDADE GERENCIAL COMO UMA IMPORTANTE FERRAMENTA DE GESTÃO: ESTUDO DE CASO DE EMPRESA VAREJISTA DA CIDADE DE PRESIDENTE PRUDENTE/SP.
}

\author{
Grace Cristina dos Santos Piccoli, Antonio Fernando Coelho, Irene Caires da Silva. \\ Universidade do Oeste Paulista - UNOESTE, Especialização em MBA Finanças e Controladoria, Presidente \\ Prudente, SP. E-mail: piccoligrace@hotmail.com, fcoelho.prof@gmail.com, irene@unoeste.br.
}

\section{RESUMO}

Com o objetivo de demonstrar e identificar a importância da Contabilidade Gerencial na gestão de uma organização empresarial, esse estudo buscou responder a seguinte pergunta: Qual a importância da Contabilidade Gerencial como ferramenta de gestão, em uma empresa varejista na cidade de Presidente Prudente/SP? A metodologia adotada foi segundo modelo exploratório de livros, artigos e web sites e através de levantamentos bibliográficos dos principais autores e estudiosos. Constatou-se que a ciência Contábil sofreu transformações ao longo dos anos, passando de um modelo estático e histórico, para um modelo dinâmico e avaliativo a gestão de negócios, utilizando se de um sistema de informações contábeis como ferramenta no suporte aos processos de tomadas de decisão. Além disso, verificou-se que a Contabilidade Gerencial permite um escopo de planejamento e controle adequado que deve ser alinhado a estratégias do negócio.

Palavras-chave: Contabilidade Gerencial. Sistema de Informações Contábeis. Gestão. Estratégia. Tomada de Decisão.

THE MANAGEMENT ACCOUNTING AS AN IMPORTANT MANAGEMENT TOOL: CASE STUDY OF RETAIL COMPANY OF THE CITY OF PRESIDENT PRUDENTE / SP.

\begin{abstract}
The article aims to demonstrate and identify the importance of Management Accounting in the management of a business organization. This study sought to answer the following question: What is the importance of Management Accounting as a management tool in a retail company in the city of Presidente Prudente/SP? The methodology adopted was the exploratory model of books, articles and web sites, as well as bibliographical surveys of the mains authors and scholars. It was contacted that the Accounting Science has undergone transformations over the years, going from a static and historical model, to a dynamic and evaluative model to business management, using and accounting information system as a tool to support the processes of making decision-making. In addition, it has been found that Managerial Accounting allows for a proper planning and control scope that must be aligned with business strategies.
\end{abstract}

Keywords: Management Accounting, Organization, Accounting Information System Management, Strategy, Decision Making. 


\section{INTRODUÇÃO}

A milhares de anos, as atividades cotidianas de caça e pesca que eram desempenhadas pelos homens primitivos tinham seus registros realizados através de desenhos em pedras em suas cavernas, ou seja, escriturações dos fatos diários que não poderiam ser esquecidos. Este comportamento dos homens pré-históricos pode ser entendido como o controle e registro de informações.

A história da Contabilidade, uma das áreas mais antigas no mundo, conta como que essa ciência social veio evoluindo desde a existência do homem. No Brasil, atualmente a Contabilidade é uma mistura de pensamentos, trazidos da Europa juntamente com as ideias americanas. Vive-se a era da inteligência e do saber, uma área profissional antiga que está buscando novos horizontes.

Marques (2008, p.13), a contabilidade pode ser descrita como "a ciência que estuda, registra, controla e analisa o patrimônio das entidades públicas, privadas e mistas".

Por ser uma ciência ampla, a Contabilidade é dividida em segmentos, e o principal objetivo desta pluralidade é estudar especificamente suas ramificações, apesar de ter o mesmo objetivo que é o de controlar o patrimônio das entidades.

Refletindo então sobre essa pluralidade, o foco deste artigo é a Contabilidade Gerencial, que se utiliza dos relatórios contábeis para quantificar e controlar o patrimônio, mas, sobretudo analisar os custos e despesas das organizações e evidenciar onde estão sendo aplicados os recursos financeiros.

Através das ferramentas utilizadas pela Contabilidade Gerencial, essa pesquisa tem por objetivo apurar como está sendo a gestão do empresário desta organização e assim fornecer informações para futuras tomadas de decisões.

\section{METODOLOGIA}

A pesquisa será conduzida segundo o modelo exploratório, qualitativo e quantitativo através de consulta a fontes primárias e secundárias, tais como: análises dos relatórios contábeis Balanço Patrimonial e Demonstração do Resultado do Exercício, acompanhamento da rentabilidade e aplicação de recursos.

Objetiva-se identificar a real situação da organização, através da análise e interpretação de indicadores de desempenho.

\section{FUNDAMENTAÇÃO TEÓRICA}

A Contabilidade é uma importante área do conhecimento científico. O sábio matemático italiano Frei Luca Paciolli, por volta do século XIII a XVI, foi o precursor da metodologia de registro e escrituração.

Já no Brasil, as instituições de nível superior foram às pioneiras no ensino da Contabilidade, baseando suas metodologias na escola italiana e posteriormente, com a vinda das empresas multinacionais americanas e inglesas, difundiu os pensamentos contábeis com a influência dos norte americanos.

Paton (apud CAMPIGLIA, 1966, p.22), destaca que a Contabilidade é sempre citada e usada como algo útil para a tomada de decisões e relata que:

Contabilidade é corpo de princípios e o mecanismo técnico por meio do qual os elementos econômicos de uma determinada organização são classificados, registrados e periodicamente apresentados e interpretados com escopo de se prover ao seu efetivo controle e à sua eficiente administração. 
Os contadores são responsáveis pela produção de documentos e relatórios confiáveis, de acordo com as mudanças ocorridas na legislação e nas boas práticas de gestão empresarial, garantindo assim a confiabilidade no âmbito mundial.

Segundo Hoss (2008, p.97):

[...] a necessidade de informações a respeito da riqueza patrimonial também sofresse mutações. Desta forma, a contabilidade passou de um conhecimento rudimentar e empírico para uma ciência onde a metodologia de escrituração e análise dos valores patrimoniais fica cada dia mais sofisticado.

Em função da variedade de empresas, segmentos de negócio, setores da economia, e em função também da nacionalidade das empresas, existem algumas técnicas contábeis que são usadas de forma mais específica - contabilidade de custos, contabilidade agrícola, contabilidade ambiental são exemplos dessa pluralidade.

O principal objetivo da Contabilidade Gerencial, outro tipo de aplicação da contabilidade, é controlar a movimentação do patrimônio por meio de indicadores e relatórios, informando em detalhes o resultado dos negócios. Os autores Marion e Osni (2011, p.3), atestam:

Para auxiliar a organização nessa conquista, surgiu à contabilidade gerencial, oferecendo detalhes de informações que até então não eram contemplados nos relatórios derivados da contabilidade.

Os mesmos Marion e Osni $(2011$, p.8) afirmam também que:

[...] conhecimento não só em contabilidade como em administração, matemática financeira, estatística e economia. Um profissional que domine bem a análise de balanços e conhecimento com detalhes as rotinas internas e os objetivos da organização, para que saiba ler os relatórios da contabilidade financeira e da gerencial, e interpretá-los conjugando dados econômicos e financeiros com operacionais, para, assim, apresentar sugestões fundamentadas que auxiliem a organização nas suas tomadas de decisões.

A Contabilidade Gerencial utiliza, como principal ferramenta de trabalho, os diversos sistemas de informação, permitindo gerar relatórios atualizados para atuar no processo decisório. Segundo Amorim (apud Turban e Volonino 2013), "um bom planejamento é necessário, mas não é suficiente e precisa ser complementado por um controle hábil. Os sistemas de informação desempenham um papel extremamente importante ao dar suporte ao controle organizacional".

Amorim (apud Padoveze, 2012) complementa: a contabilidade gerencial "avalia resultados empresariais e o desempenho dos gestores, em todas as etapas do processo de gestão". Portanto, o gerenciamento financeiro atua como instrumento de prestação de contas ao empresário, dando suporte decisório e influenciando o comportamento gerencial.

\section{RESULTADOS}

A empresa Ômega Conveniência (nome fictício) foi fundada em 01 de julho de 2002, está situada na região sul da cidade de Presidente Prudente/SP, possui onze colaboradores, seu objeto social é o comércio varejista de bebidas e produtos alimentícios em geral, e tem como público cativo os consumidores noturnos de bebidas.

Abaixo apresentamos o diagnóstico da empresa utilizada como modelo nesta pesquisa, analisando os seguintes indicadores financeiros: Liquidez, Rentabilidade, Endividamento e Solvência. 
Gráfico 1. Índices calculados a partir dos balanços patrimoniais de 2016 /2017

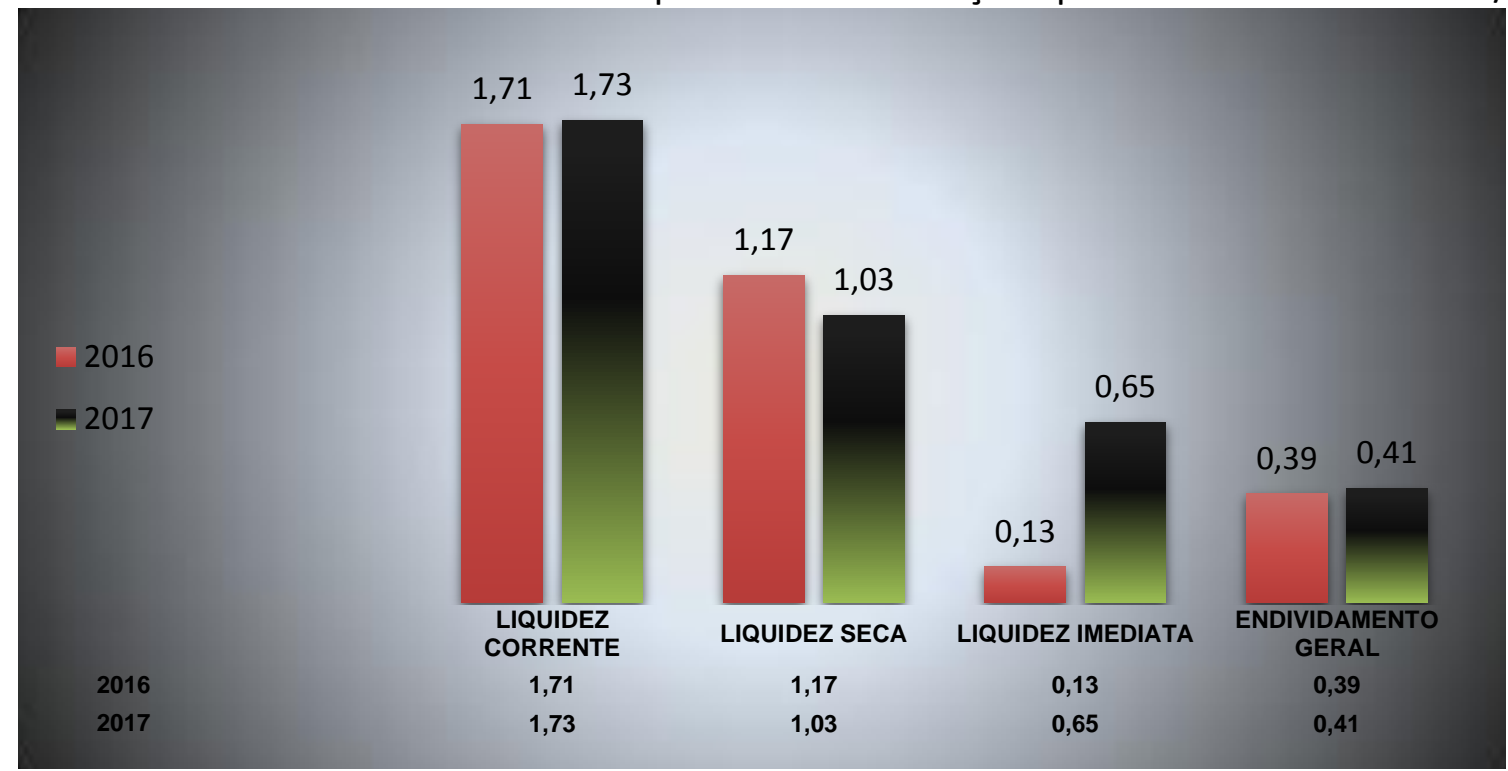

Fonte: Elaborado pela autora

Houve ligeiro crescimento no Índice de Liquidez Corrente referente aos anos de 2016 e 2017: foi de $R \$ 1,71$ para $R \$ 1,73$, ou seja, para cada $R \$ 1,00$ de obrigações o ativo circulante paga as obrigações contraídas com ativos de curto prazo, com sobra de médios $\mathrm{R} \$ 0,72$ por cada real.

As contas caixa, bancos, estoques e aplicações financeiras que compõem o ativo circulante foi o motivo pelo resultado positivo. O Caixa em 2016 era de $R \$ 34.489,83$ passando em 2017 para $\mathrm{R} \$ 170.995,96$, e a conta Banco em 2016 era de $\mathrm{R} \$ 77,87$ passando a $\mathrm{R} \$ 10.070,89$. Os Estoques contribuíram também para a melhoria neste índice, pois em 2016 era de $R \$ 146.848,97$ e em 2017 evoluiu $R \$ 195.321,67$. Em linhas gerais o ativo circulante aumentou $\mathrm{R} \$ 18.518,73$, e o aumento do passivo circulante entre os dois períodos foi inexpressivo, apenas $R \$ 8.383,84$. Essa movimentação financeira foi bastante positiva.

Já a variação no Índice de Liquidez Seca - que é a capacidade de pagamento utilizando somente os saldos monetários - demonstra declínio nos resultados; no ano de 2016 estava em $R \$ 1,17$ e em 2017 diminuiu para $R \$ 1,03$. Em uma análise fria, significa que para cada $R \$ 1,00$ de dívidas a empresa tem $R \$ 1,03$ de recursos monetários para pagamento.

Analisando agora o Índice de Liquidez Imediata ou Instantânea, descobre-se que houve crescimento significativo nos resultados; em 2016 estava em R\$0,13 passando para $R \$ 0,65$ em 2017, elevando assim a capacidade da empresa em sanar suas obrigações a curtíssimo prazo.

O Índice de Rentabilidade apresenta crescimento, no ano de 2016 era de $\mathrm{R} \$ 4,90$ já em 2017 foi para $R \$ 6,15$, ou seja, houve crescimento no retorno do capital investido pelo proprietário: para cada real investido na empresa o retorno foi de $\mathrm{R} \$ 6,15$. A análise da rentabilidade também pode ser feita observando o gráfico abaixo: 
Gráfico 2. Retorno sobre o patrimônio líquido 2016/2017

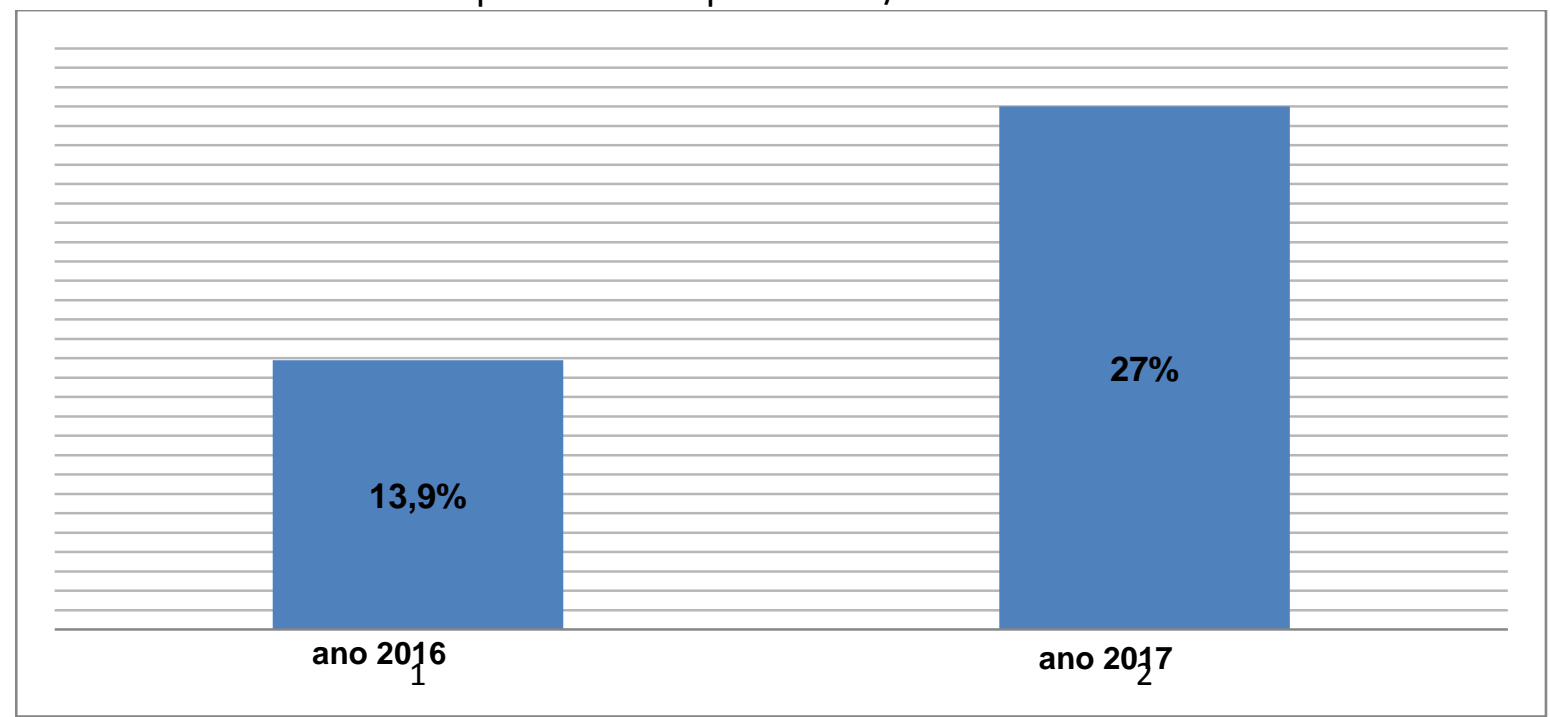

Fonte: Elaborado pela autora

No quesito Margem Líquida, em 2016 o índice foi de 1,74\% (lucro líquido de $\mathrm{R} \$ 59.297,18$ dividido pelas vendas de $\mathrm{R} \$ 3.469 .997,21)$. Já no ano de 2017 esse percentual representou 2,59\% (lucro líquido de $\mathrm{R} \$ 108.924,79$ em relação as receitas de $\mathrm{R} \$ 4.286 .712,36)$. Essa variação contribuiu também o alcance de ótimos resultados financeiros.

Complementando o estudo, um dos indicadores mais precisos para analisar a saúde financeira das empresas é o Termômetro de Kanitz, criado por Stephen Charles Kanitz, consultor brasileiro com mestrado em Administração pela Universidade de Harvard. Ele é o precursor na análise de risco de crédito avaliando um possível ou não pedido futuro de falência ou concordada. A Insolvência é a falta de liquidez ou o não cumprimento de obrigações; no caso de falência é uma situação não temporária.

Tabela 1. Índice Insolvência

Fonte: Elaborado pela autora

\begin{tabular}{|l|l|l|}
\hline \multirow{2}{*}{ ÍNDICE INSOLVÊNCIA R\$ } & 2016 & 2017 \\
\cline { 2 - 3 } & 4,54 & 4,00 \\
\hline
\end{tabular}

A análise de insolvência demonstra que houve redução, apesar de irrelevante, no período sob análise: em 2016 era $\mathrm{R} \$ 4,54$ e em 2017 diminuiu para $\mathrm{R} \$ 4,00$. 
Figura 1. Termômetro de Kanitz

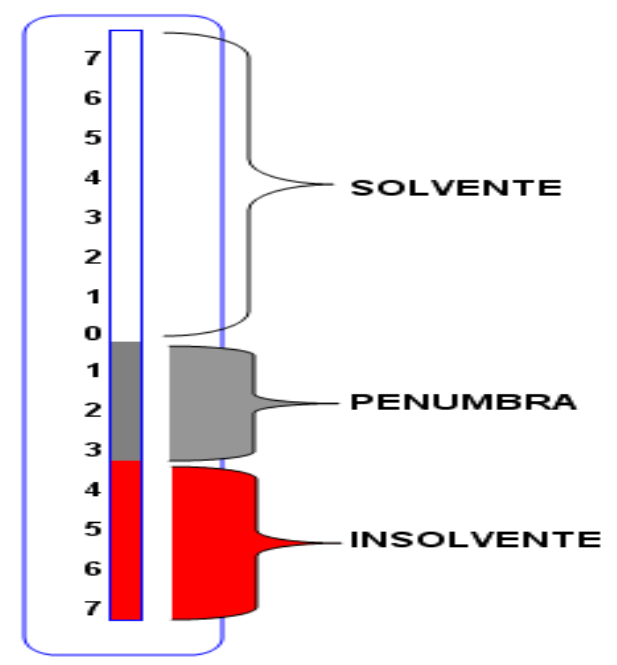

Fonte: SILVA (2002) - Adaptado pela autora

Pelo Termômetro de Kanitz a empresa estudada se manteve no nível +4 e =4 durante o período 2016 - 2017, sendo assim podemos afirmar que a mesma se encontra distante da possibilidade de uma possível falência.

\section{DISCUSSÃO}

A maioria das empresas de pequeno porte tem como seu administrador principal, o próprio empresário, que com sua restrita experiência na área de gestão encontra dificuldade para utilizar ferramentas avançadas de análise, inclusive os indicadores financeiros, os quais produzem dados importantes que transformam simples informações em fonte rica de conhecimento, alicerçando as tomadas de decisão.

A contabilidade é uma ciência ampla, o seu objeto de estudo é o universo patrimonial e financeiro de uma organização, e assim o profissional contabilista deve possuir conhecimento da estrutura da empresa para desempenhar um trabalho seguro e confiável, fornecendo informações corretas, completas e oportunas ao empresário. Através da análise das demonstrações contábeis, valiosa ferramenta gerencial, permite-se visão ampla dos negócios e permite a correta obtenção e aplicação dos recursos, na realização das metas da organização.

\section{CONCLUSÃO}

Através de cálculos matemáticos efetuamos a análise dos demonstrativos, e os índices estudados revelam a real situação da empresa.

Verificou-se através desse estudo de caso que, durante os anos de 2016 e 2017 a empresa Ômega Conveniência está com sua situação financeira em total estabilidade, os índices de liquidez demonstram que se a empresa encerrasse suas atividades hoje conseguiria quitar suas dívidas em curto, médio e longo prazo.

No diagnostico temos que a empresa Ômega Conveniência é uma organização estável, que se encontra com um índice de solvência elevado e o fator de insolvência encontra-se fora de risco, ou seja, esta organização encontra-se com ótima capacidade de pagamento e longe de uma falência empresarial. 


\section{REFERÊNCIAS}

LUIZ MARQUES, W. Conhecendo Contabilidade. 1으. Ed. Cianorte, PR Gráfica Vera Cruz: 2008.

OSWALDO CAMPIGLIA, A. Contabilidade Básica. Ed. Universidade de São Paulo São Paulo: 1966.

HOSS, O. Contabilidade: ensino e decisão. São Paulo: Atlas: 2008

MARION, J. C.; RIBEIRO, O. M.; Introdução a Contabilidade Gerencial. Saraiva, São Paulo: 2011.

BARBOSA SILVA, J. Demonstrações Financeiras. 5o Ed. São Paulo, SP, Atlas: 2002.

TÓFOLI, I. Administração Financeira Empresarial. 1 Ed. São José do Rio Preto, SP, Raízes: 2012.

A IMPORTÂNCIA DA CONTABILIDADE GERENCIAL PARA GESTÃO DOS NEGÓCIOS. Disponível em:

https://semanaacademica.org.br/system/files/artigos/artigo contabilidade gerencial $0 . p d f$ >. Acesso em: 29 jul. 2018. 